\title{
Perception And Use Of Intrauterine Contraceptive Devices (IUCD) Among Married Women Of Reproductive Age In Bhaktapur, Nepal
}

This article was published in the following Dove Press journal: Open Access Journal of Contraception

\author{
Bijay Khatri $\mathbb{D}^{\prime}$ \\ Anjana Khadka ${ }^{2}$ \\ Archana Amatya ${ }^{3}$ \\ Sushan Man Shrestha $\mathbb{1 D}^{4}$ \\ Rajan Paudel ${ }^{4}$ \\ 'Academic and Research Department, B.P. \\ Eye Foundation, Kathmandu, Nepal; \\ ${ }^{2}$ Department of Health Services, Ministry of \\ Health, Kathmandu, Nepal; ${ }^{3}$ Save the \\ Children International, Nepal Country \\ Office, Kathmandu, Nepal; ${ }^{4}$ Central \\ Department of Public Health, Institute of \\ Medicine, Tribhuvan University, Kathmandu, \\ Nepal
}

Purpose: The copper-T (TCu-380A), an intrauterine contraceptive device (IUCD), is widely available and is highly effective in terms of safety and effectiveness. Despite this fact, there is low utilization of IUCD in Nepal. This paper describes the perception and use of IUCD among married women of reproductive age attending an institutional clinic in Bhaktapur, Nepal.

Methods: An institution-based cross-sectional study was conducted among 273 married women attending the institutional clinic of Bhaktapur hospital who were interviewed by trained staff nurses using semi-structured questionnaires. Systematic random sampling method was applied to select the participants. Logistic regression analysis was used to determine the relationship between factors associated with utilization of IUCD.

Results: Just below half (48.7\%) of the participants had heard about IUCD. Only $7.0 \%$ of the potential users were currently using IUCD, and all of them had discussed using it with their husbands. Among women aware of IUCD, nearly a quarter of them $(23.8 \%)$ did not want to use it because of their husband's disapproval and their assumed fear of decreased sexual pleasure. There was a significant association between previous abortion and use of IUCD, where the women who had a history of abortion had increased odds of using the IUCD by 5.45 -times compared to those who had not $(p=0.01)$. The women who were counseled about IUCD by health workers were 2.83-times more likely to use an IUCD than those who were not. The women who had a good knowledge level about IUCD as a method of modern contraception had 2.85-times increased odds of using the IUCD compared to those who had poor or no knowledge about it.

Conclusion: The use of IUCD depends on the support of husbands, knowledge about its safety, efficacy, and counseling.

Keywords: husband, abortion, counseling, knowledge

\section{Introduction}

The Family Planning (FP) program to control the population began some six decades ago, initially focused on increasing contraceptive uptake among nonusers. Currently, the outcome of the FP program has spread its wings to such an extent that the access to FP services has been recognized as critical to the health, well-being, and autonomy of women. ${ }^{1}$ Moreover, investing in FP has now been dubbed as a best buy in development which can play a key role in achieving the Sustainable Development Goals. ${ }^{2}$

Globally, in 2012, four in ten pregnancies were unintended, of which $50 \%$ ended in abortion and $13 \%$ in miscarriage. ${ }^{3}$ The World Health Organization is explicitly
Correspondence: Bijay Khatri Academic and Research Department, B.P. Eye Foundation, Kathmandu, Nepal Tel +977984I463005

Email bj.khatri@gmail.com 
clear that under no circumstances should induced abortion be used as a means of FP. Unintended pregnancies are an important public health issue due to their negative association with social and health outcomes for both mothers and children, ${ }^{4}$ and nearly half of them are due to inconsistent or incorrect contraceptive use. ${ }^{5}$ In 2014 in Nepal, half of all pregnancies were unintended and $62 \%$ of those ended in abortion. ${ }^{6}$

At least one in ten married or in-union women worldwide have an unmet need for FP, whereas in the least developed countries it is one in five. ${ }^{7}$ The Nepal Demographic and Health Survey (DHS) shows that Nepal has a stagnated prevalence of modern contraceptive use of about $44 \%$ to $43 \%$ from 2006 to 2016 . In 2016 , one in four married women have an unmet need for FP, $8 \%$ wanting to delay childbearing, and another $16 \%$ wanting to stop childbearing. ${ }^{8}$ In the same year in Nepal, only $15 \%$ of currently married women aged $15-19$ used a modern method of contraception, while $17 \%$ of the same age-group were already mothers or pregnant with their first child. $^{8}$

The intrauterine contraceptive methods are top tier contraceptives as they are long-lasting, convenient, wellliked by users, cost-effective, unobtrusive, reversible, and have failure rates less than $1 \%$ per year for perfect and typical use, rivaling the efficacy of permanent tubal sterilization. ${ }^{9}$ The American College of Obstetricians and Gynecologists reports that complications of intrauterine contraceptive devices (IUCDs) are rare and differ little between adolescents and women, making it safer for adolescents' use as well. ${ }^{10}$ The IUCDs are very safe, effective, and convenient for postpartum, post-abortion, non-pregnant, and breastfeeding mothers. While it is not protective against Human Immunodeficiency Virus (HIV) transmission, it is safe in HIV infected women. It is equally effective and safe for use in the young and/or nulliparous, older women, and women unable to use hormonal methods for preventing pregnancy. ${ }^{11,12}$ In addition to its use for long-term contraception, it is also the most effective form of emergency contraception. ${ }^{13}$

In Nepal, the most widely available IUCD is the TCu380A (Copper T). This is a T-shaped plastic device with $380 \mathrm{~mm}$ of copper wire wrapped around the stem and arms and is approved for up to 10 years of continuous use. ${ }^{14}$ The Nepal DHS of 2016 showed that $84 \%$ of women aged 15-49 were aware of the IUCD, but only $1.1 \%$ were using it. ${ }^{8}$ Despite its widespread availability, awareness, safety, effectiveness, and advantages, there is low utilization rate of IUCD in Nepal. The underlying causes of low IUCD use needs exploration for better understanding so that the reproductive health programs can appropriately address the issues. Hence, this study was conducted to find the perception about IUCD use among married women of reproductive age.

\section{Methodology}

This hospital based descriptive cross-sectional study was conducted from January to March 2017. The institutional clinic of Bhaktapur Hospital, Bhaktapur was selected purposely as it was the only government clinic in the district providing every modern FP service in the district. The study participants were married women of reproductive age (MWRA) between 15-49 years of age attending the clinic. Participation was voluntary, receiving no incentives for participating in the study. The sample size was determined using the single population formula, based on an estimated $23 \%$ modern temporary contraceptive usage among MWRA (pregnant and sterilized couples excluded) in the Bhaktapur district, ${ }^{15}$ with the assumption of $95 \%$ confidence interval (CI), 5\% margin of error, and 5\% nonresponse rate, which yielded the sample size to be 286 .

The daily Outpatient Department register of the clinic was used to select the sampling frame and a systematic random sampling method was applied to select the participants. Willing participants were interviewed by trained female staff nurses during their waiting period. Based on a secondary data review of the last 3 fiscal years, the clinic had an average of 810 service users per month during the months of January-March. The first participant was selected by lottery method and then every third patient was asked to participate in the study. Pregnant women and women or their husband who had surgical sterilization for permanent FP method were excluded from the study.

The semi-structured questionnaire was developed to meet study objectives considering the contents of previously used study tools, and from the literature review. After preparation of the draft questionnaire, a set of questions and the study proposal were sent to an obstetrician and gynecologist, a senior family planning service provider and a public health nurse for expert review and revised according to their suggestions. The questionnaire in Nepali language was pre-tested among 20 MWRA attending an urban health clinic from the same district.

The data was collected by face-to-face interview using a validated questionnaire by female staff nurses, ensuring acceptable privacy for the participants. These enumerators were 
given 2 days comprehensive training to assure uniform methods of approaching the potential participants, explaining the nature of information needed, taking written consent, extracting the information through interviewing, and writing the information on the semi-structured questionnaire. Any potential participants under the age of 18 were briefed about the study in the presence of their escorts, and written consent was taken from the escort before the start of the interview.

The interviewers were also trained to provide accurate information about IUCD and FP with the help of leaflets from the Information Education Communication corner of the clinic to the participants at the end of interview.

The outcome variable, current use of IUCD, was assessed by directly questioning the participant about the method of family planning she or her husband was currently using.

The explanatory variables in this study were:

(a) Age group: The participant was asked about her current age and categorized as 15-24 years; 25-34 years, or 35-49 years.

(b) Educational status: The participant was asked about her and her husband's educational status, and categorized as either illiterate or literate (able to read and write); level of school education (up to grade XII); or university education.

(c) History of abortion: The participant was asked if she had ever had abortion, and was categorized as yes or no.

(d) Parity: The participants were asked about the numbers of living children she had during the time of the study, and was categorized as only one living child or more than one.

(e) Previous use of modern contraception: The participant was asked about the previous family planning method used by the participant or her husband prior to the current one and categorized as yes or no. The male condoms, Oral Contraceptive Pills, Injectable Contraceptives, Contraceptive Implants, and IUCDs were taken into account as modern contraceptive methods in this study.

(f) Availability of IUCD services at the nearest government health facility: The participant who was aware about IUCD as a method of modern contraceptive was asked about the availability of IUCD services at the nearest government health facility (within 30 minutes walking distance) and was categorized as yes or no. (g) Discussion about use of IUCD with husband: The participant who was aware about IUCD as a method of modern contraceptive was asked if she ever discussed with her husband about the possible use of IUCD as a method of contraceptive and was categorized as yes or no.

(h) Counseled on using IUCD: The participant who was aware about IUCD as a method of modern contraceptive was asked if she was ever counseled by any health workers or peers or colleagues or relatives about using IUCD as a method of contraceptive.

(i) Knowledge level about IUCD: The participant who was aware about IUCD as a method of modern contraception was asked seven general statements with the replies as true or false, from which the participant's knowledge level was determined.

The completed questionnaires were checked daily by the corresponding author for completeness, legibility, and consistency. Data entry was done using EpiData 3.1, and analyses were done using IBM Statistical Package for Social Science (SPSS) 23 software. The frequencies and percentage were computed to assess the distribution of sample characteristics including age group, educational status, family planning methods use, source of contraceptives, reason for current use of contraceptives, reasons for stopping use of IUCD, and reason for not wanting to use IUCD in the future. To determine the factors associated with current use of IUCD, a two-step modeling approach was undertaken. First, bivariate logistic regression analyses of each explanatory variable and outcome variable were conducted to identify the associations. Second, those variables with $p$-values $<0.2$ were included in a multivariate logistic regression analysis to determine the effect adjusted for each of the other potential explanatory variables. A $p$-value of $<0.05$ denoted statistical significance in the final model.

The ethical approval was obtained from the Institutional Review Board of the Institute of Medicine, Tribhuvan University for this study. The permission was taken from the Hospital Management Committee of Bhaktapur Hospital before collecting the data. The health workers at the clinic were briefed on the purpose of the study. 
The purpose of the study and the nature of information needed were explained to the participants before taking written consent. The participants were assured of confidentiality of the information and informed about their right to skip questions or withdraw anytime from the interview.

\section{Results}

Among 286 MWRA approached for interview, only 273 completed the interview. The mean age of participants was $28.8 \pm 6.5$ years and their mean age of marriage was 19.1 \pm 2.7 years. More than half $(52.4 \%)$ of them were in the age-group 25-34 years old and all the participants were literate as well as their husbands, as shown in Table 1.

Every participant had at least one living child and $56.8 \%$ had two or more children. Among all participants, just above one in ten (11.0\%) had a history of abortion, as shown in Table 2.

At the time of the interview, one third of the participants $(33.3 \%)$ reported not using any of the modern forms of temporary FP methods. Among 182 modern contraceptive users; three in five $(60.4 \%)$ participants were using the injectable contraceptives, more than seven in ten of the users $(72.0 \%)$

Table I Socio-Demographic Characteristics Of The Participants

\begin{tabular}{|l|l|l|}
\hline Characteristics & Frequency & Percentage \\
\hline Age group & & \\
I5-24 years old & 77 & 28.2 \\
$25-34$ years old & 143 & 52.4 \\
$35-49$ years old & 53 & 19.4 \\
\hline Educational status & & \\
Able to read and write & 206 & 75.5 \\
School education & 41 & 15.0 \\
Attended university & 26 & 9.5 \\
\hline Husband's educational status & & \\
Able to read and write & 137 & 50.2 \\
School education & 87 & 31.9 \\
Attended university education & 49 & 17.9 \\
\hline
\end{tabular}

Table 2 Reproductive Health Characteristics Of The Participants

\begin{tabular}{|l|l|l|}
\hline Characteristics & Frequency & Percentage \\
\hline Parity & & \\
Only one child & 118 & 43.2 \\
Two or more children & 155 & 56.8 \\
\hline History of abortion & & \\
At least once & 30 & 11.0 \\
Never & 243 & 89.0 \\
\hline
\end{tabular}

wanted to limit the number of births, and the government health facility was the major source (79.7\%) of contraceptives, as presented in Table 3.

Just below half $(48.7 \%)$ of the participants responded that they had heard about IUCD or Copper-T when described to them. Among all participants, only 19 women $(7.0 \%)$ were using IUCD during the time of interview, and each of them had discussed using it with their husband before using them.

Despite the awareness of IUCD as modern contraceptive method, 98 participants did not want to use IUCD in the future. Among them more than four in ten $(42.8 \%)$ had fear of its side-effects on health, about three in ten (31.6\%) replied they did not have sufficient knowledge about IUCD to choose it as a modern contraceptive method and nearly one fourth (23.5\%) of them reported their husband's disapproval to use it and their fear of decreased sexual pleasure, as depicted in Table 4.

Table 3 Family Planning Characteristics Of The Participants

\begin{tabular}{|l|l|l|}
\hline Characteristics & Frequency & Percentage \\
\hline $\begin{array}{l}\text { Current modern contraceptive } \\
\text { methods }\end{array}$ & & \\
Oral contraceptive pills & 12 & 6.6 \\
Injectable contraceptives & 110 & 60.4 \\
Male condoms & 9 & 4.9 \\
IUCD or Copper T & 19 & 10.4 \\
Implant & 32 & 17.6 \\
\hline Reason for using current & & \\
contraceptive & & \\
To space birth & 51 & 28.0 \\
To limit birth & 131 & 72.0 \\
\hline Site of current contraceptive & & \\
services & & \\
Government health facilities & 145 & 79.7 \\
NGO run FP clinic & 21 & 11.5 \\
Private health facilities and & 16 & 8.8 \\
pharmacy & & \\
\hline
\end{tabular}

Table 4 Reasons For Not Wanting To Use IUCD In Future

\begin{tabular}{|l|l|l|}
\hline Statements & Frequency & Percentage \\
\hline Fear of side-effects on health & 42 & 42.8 \\
Lack of sufficient knowledge & 31 & 31.6 \\
Husband's disapproval and fear of & 23 & 23.5 \\
decreased sexual pleasure & & \\
Planning for permanent sterilization & 2 & 2.1 \\
\hline
\end{tabular}


Table 5 Reasons For Discontinuation Of IUCD

\begin{tabular}{|l|l|l|l|}
\hline Statements & $\begin{array}{l}\text { Average } \\
\text { Use } \\
\text { (Duration } \\
\text { In Months) }\end{array}$ & Frequency & Percentage \\
\hline $\begin{array}{l}\text { To get pregnant } \\
\text { again } \\
\text { Husband went } \\
\text { abroad } \\
\text { Side-effects or } \\
\text { health concern }\end{array}$ & 20.1 & 7 & 58.3 \\
\hline
\end{tabular}

Only 12 women had previously used IUCD, and more than half $(58.3 \%)$ of them stopped using it to get pregnant once again, one-fourth $(25.0 \%)$ of them stopped using it after their husband went abroad for jobs opportunity and two of them reported side effects or health concern as shown in Table 5. No participant reported an IUCD failure in this study.

We analyzed the association of each variable with IUCD use independently and calculated Crude Odds Ratio (COR), and interactively with the other variables to calculate Adjusted Odds Ratio (AOR), as shown in Table 6.

The bivariate analysis showed that education levels of the woman and her husband, history of abortion, previous use of modern contraceptive, counseling, and access of IUCD services and knowledge level of IUCD were significantly associated with current use of IUCD.

Interestingly, the logistic regression model suggested that the history of abortion was the only variable found to be significantly associated with current IUCD use.

The age and education of women had a modest effect on IUCD usage, increasing with age and level of education. But the women whose husbands had university education were nearly twice as likely to use IUCD. The women with a history of abortion were five times more likely to use IUCD than those who had never encountered abortion. The women with at least two or more living children had increased odds by more than three times to use IUCD than those who had only one living child. The women residing within walking distance of a government health facility with IUCD services were twice as likely to use IUCD, but there was no difference among women with previous use of any modern contraceptives by themselves or their husbands or not.

The women who had been counseled about IUCD by health workers and those with a good knowledge level about IUCD had 2.83- and 2.85-times increased odds over those who were counseled by others than health workers and who had no or poor knowledge level about IUCD, respectively.

\section{Discussion}

Only $7.0 \%$ of women surveyed were using IUCDs at the time of interview, and all of the IUCD users had discussed using it with their husbands. Among previous users of IUCD, no one reported IUCD failure, whereas one-fourth of them stopped using it after their husband went abroad for job opportunities. Both independent and multivariate analysis showed significant associations between the women who had a history of abortion, who were 5.45times more likely to use IUCD than those who had never had an abortion. Independent analysis showed that women who had been counseled about IUCD by health workers were nearly 2.83 -times more likely to use IUCD than those who were counseled by other people like peers, colleagues, relatives, or had never heard of it. Similarly, the women who had good knowledge levels about IUCD use as a method of modern contraceptive had 2.85-times increased odds of using IUCD compared with those who had a poor level or no knowledge about it.

In our study, $7.0 \%$ were using IUCD as a means of birth control, which is similar to the $6.5 \%$ of Bhaktapur. ${ }^{15}$ Both of these are higher compared to the findings from Nepal DHS $2016,{ }^{8}$ where only $1.8 \%$ of a similar group of women were using it as a method of contraception. The higher proportion of IUCD users in this study might be due to the literacy status, urban setting, and hospital-based study.

All IUCD users in this study had discussed using it with their husbands. On the contrary, 23.5\% of women who were not willing to use IUCD in future cited their husband's disapproval to use it due and their fear of decreased sexual pleasure. These findings show the importance of engaging husbands in counseling about IUCD use.

Among 12 previous users of IUCD in our study, 58.3\% stopped using IUCD to get pregnant. The proportion of women stopping IUCD was similar to a 2012 study in Jaipur, India, ${ }^{16}$ where $55.13 \%$ stopped IUCD use because of their desire to conceive. More than one-third (34.0\%) in 2011 discontinued IUCD for the same reason in Pakistan, ${ }^{17}$ while $12.2 \%$ also wanted a child in another study in Nepal. ${ }^{18}$ This is the appeal of reversible contraceptives like IUCD where spacing is critical for well-being 
Table 6 Association Between Different Independent Variables And Utilization Of IUCD

\begin{tabular}{|c|c|c|c|c|c|c|}
\hline \multirow[t]{2}{*}{ Variables } & \multicolumn{2}{|c|}{ Current Utilization Of IUCD } & \multirow[t]{2}{*}{$p$-value } & \multirow[t]{2}{*}{ COR } & \multirow[t]{2}{*}{ AOR } & \multirow[t]{2}{*}{$p$-value } \\
\hline & Yes (\%) & No (\%) & & & & \\
\hline \multicolumn{7}{|l|}{ Age } \\
\hline 15-24 years old & $2(10.5)$ & $75(29.5)$ & & $\mathrm{I}$ & I & \\
\hline $25-34$ years old & $12(63.2)$ & $|3|(5 \mid .6)$ & 0.11 & $3.44(0.75-15.76)$ & $0.99(0.12-7.87)$ & 0.99 \\
\hline $35-49$ years old & $5(26.3)$ & $48(18.9)$ & 0.11 & 3.91 (0.73-20.95) & $1.43(0.16-12.83)$ & 0.75 \\
\hline \multicolumn{7}{|l|}{ Education } \\
\hline Able to read and write & $10(52.6)$ & $196(77.2)$ & & 1 & I & \\
\hline School education & $2(10.5)$ & $39(15.4)$ & 0.99 & $\mathrm{I} .0 \mathrm{I}(0.2 \mathrm{I}-4.77)$ & $0.46(0.06-3.50)$ & 0.46 \\
\hline $\begin{array}{l}\text { Attended university } \\
\text { education }\end{array}$ & $7(36.8)$ & $19(7.5)$ & $<0.001^{\mathrm{a}}$ & $7.22(2.47-21.15)$ & $3.70(0.4 \mid-33.06)$ & 0.24 \\
\hline \multicolumn{7}{|l|}{ Husband's education } \\
\hline Able to read and write & $7(36.8)$ & $130(5 \mid .2)$ & & 1 & 1 & \\
\hline School education & $3(15.8)$ & $84(33.1)$ & 0.56 & $0.66(0.17-2.64)$ & $0.67(0.13-3.59)$ & 0.64 \\
\hline $\begin{array}{l}\text { Attended university } \\
\text { education }\end{array}$ & $9(47.4)$ & $40(15.7)$ & $0.01^{\mathrm{a}}$ & $4.18(1.46-11.93)$ & $1.98(0.25-15.72)$ & 0.52 \\
\hline \multicolumn{7}{|l|}{ History of abortion } \\
\hline Yes & $8(42.1)$ & $22(8.7)$ & $<0.00 \mathrm{I}^{\mathrm{a}}$ & $7.67(2.79-21.06)$ & $5.45(1.63-18.17)$ & $0.01^{\mathrm{b}}$ \\
\hline Never & II (57.9) & $232(91.3)$ & & 1 & I & \\
\hline \multicolumn{7}{|l|}{ Parity } \\
\hline Only one living child & $5(26.3)$ & II $3(44.5)$ & & I & 1 & \\
\hline Two or more living children & 14 (73.7) & $|4|(55.5)$ & 0.13 & $2.24(0.79-6.42)$ & $3.68(0.74-18.34)$ & 0.11 \\
\hline \multicolumn{7}{|l|}{$\begin{array}{l}\text { IUCD services available at } \\
\text { nearby Government } \\
\text { Health Facility (within } 30 \\
\text { minutes walking distance) }\end{array}$} \\
\hline Yes & II (57.9) & $56(22.0)$ & $0.00^{\mathrm{a}}$ & $4.86(1.87-12.67)$ & $2.18(0.61-7.80)$ & 0.23 \\
\hline No & $8(42.1)$ & $198(78.0)$ & & 1 & 1 & \\
\hline \multicolumn{7}{|l|}{$\begin{array}{l}\text { Previous use of modern } \\
\text { contraceptive methods }\end{array}$} \\
\hline Yes & $16(84.2)$ & $173(68.1)$ & $0.16^{\mathrm{a}}$ & $2.50(0.7 I-8.8 I)$ & $1.02(0.15-6.82)$ & 0.99 \\
\hline No & $3(15.8)$ & 81 (31.9) & & $\mathrm{I}$ & 1 & \\
\hline \multicolumn{7}{|l|}{ Counseled to use IUCD } \\
\hline Health Workers & $12(63.2)$ & $57(22.4)$ & $<0.00 \mathrm{I}^{\mathrm{a}}$ & $5.93(2.23-15.75)$ & $2.83(0.75-10.66)$ & 0.12 \\
\hline $\begin{array}{l}\text { Others than health } \\
\text { workers }\end{array}$ & $7(36.8)$ & 197 (77.6) & & 1 & 1 & \\
\hline \multicolumn{7}{|l|}{$\begin{array}{l}\text { Knowledge level about } \\
\text { IUCD }\end{array}$} \\
\hline Good & 14 (73.7) & $91(35.8)$ & $0.00^{\mathrm{a}}$ & $5.02(1.75-14.37)$ & $2.85(0.58-13.99)$ & 0.23 \\
\hline Poor & $5(26.3)$ & $163(64.2)$ & & $\mathrm{I}$ & I & \\
\hline
\end{tabular}

Notes: ${ }^{a} p<0.05$, significance in bivariate analysis. ${ }^{b} p<0.05$, significance in multivariate analysis.

of the women wanting to conceive, her previous child, and her future child as well as that family.

However, one-fourth $(25.0 \%)$ of the previous users of IUCD in this study stopped using it after their husband went abroad for job opportunities, which is higher than another study from Nepal, ${ }^{18}$ where $9.6 \%$ stopped for the same reason. This is the most common reason for discontinuing any family planning method in Nepal, ${ }^{8}$ as many Nepali men of reproductive age are employed temporarily abroad due to ever shrinking opportunities in Nepal. 
Meanwhile, $16.7 \%$ discontinued using IUCD within 5 months of insertion in this study due to side-effects or health concerns, which is similar to a finding from a 2012 study in Kathmandu, Nepal where 19.1\% discontinued for the same reason. ${ }^{19}$ In contrast, $38.3 \%$ reported health concerns for discontinuation in another study in Nepal ${ }^{18}$ whereas nearly half of the women $(49.8 \%)$ discontinued using in Pakistan quoting similar concerns. ${ }^{17}$ In 2016, a nationwide survey in $\mathrm{Nepal}^{8}$ showed that $62 \%$ of women cited side-effects or health concerns as a reason for discontinuing IUCD use. In our study, there were just two participants discontinuing IUCD use in this study, which is not sufficient to make generalizations. It is possible that IUCD service providers in Nepal have poor knowledge about medical eligibility for IUCD insertion, as shown in a study ${ }^{20}$ suggesting that there may be a need to improve and update healthcare providers' knowledge about IUCD for better counseling and IUCD service provisions.

Among the participants who were aware about IUCD as a modern contraceptive but not willing to use it, nearly half $(48.25 \%)$ mentioned the fear of its side-effects on health, $31.6 \%$ of them replied they did not have sufficient knowledge to choose it as a contraceptive method, and $23.5 \%$ of women reported the husband's disapproval to use it and their fear of decreased sexual pleasure. These issues are similar to findings from a study in Kathmandu Valley, Nepal, where $30.0 \%, 31.8 \%$, and $6.4 \%$ of the women referred to fear of side-effects on health, lack of information, and husband disapproval, respectively, for not using IUCD. ${ }^{21}$

These findings confirm an important need for relevant information and counseling for eligible couples regarding the use, safety, side-effects, and risks of IUCD use, so that they may be better able to make informed decisions on the best form of contraception for their needs. Currently, FP knowledge and awareness among many Nepali couples is gained by consulting their friends/relatives for this, whose information may increase misconceptions and fears rather than accurate information.

Age is an important factor associated with IUCD use, where older women (35-49 years old) were more likely to use the device than younger. The usage by older women in our study was almost 1.5-times the rate in younger women (15-24 years old), not quite as high as another study based in Bahir Dar, Ethiopia, where older women were almost 5.5-times as likely to select IUCDs. ${ }^{22}$ Our findings are consistent with the Nepal Multiple Indicator Cluster Survey (MICS), ${ }^{23}$ which showed increased use of IUCD with increase in age group from 15-19 to 35-39 years, as well as the latest Nepal DHS, ${ }^{8}$ which also reported that use of IUCD increased with increase in age-group from 15-19 to 45-49 years among MWRA. This is expected, as increased maternal age is associated with having more children, so maternal interest in spacing or limiting further children may be important factors for birth control selection. The women who had two or more living children had 3.68-times increased odds to use IUCD than those who had only one living child. This is consistent with a study conducted in Kathmandu Valley, Nepal where the women with two or more children were more than twice (2.2times) as likely to use IUCD than with only one child. ${ }^{21}$ This might be due to Nepalese families preferring two child norms as in most community and which is also advocated by the government.

In terms of educational status, the women who had attended university education had 3.7-times increased odds of using IUCD compared to women who were only literate. In a study in North West Amhara, Ethiopia, the women who had attended college were 21.24-times more likely to use IUCD than those who could not read or write. $^{22}$ The Nepal MICS ${ }^{23}$ and DHS ${ }^{8}$ also showed an increase in IUCD use with an increase in educational status of women. Likewise, in our study, if the women's husband had university education, they were nearly 2times more likely to use IUCD than those who were only able to read and write. Clearly, educational attainment is an important determining factor, likely because they are more able to and participate in discussing the importance of family planning, small family sizes, birth spacing, and choosing the best available contraceptive method after counseling.

Meanwhile, in this study there was a significant association between abortion and use of IUCD. The women who had a history of abortion were 5.45-times more likely to use IUCD compared to those who had not. To the best of our knowledge, studies reporting a similar relationship were not found in the literature search. In a study in New Zealand among young women seeking abortion, 43.3\% intended to use IUCD post-abortion, ${ }^{24}$ which was similar to a study in China where $35.2 \%$ intended to use IUCD in the immediate post-abortion period. ${ }^{25}$ The Cochrane Database of Systematic Review also has concluded that insertion of an IUCD immediately after abortion is safe and practical. ${ }^{26}$ The abortion center appears to be an opportunity to counsel and provide modern contraceptives such as IUCD to the couple or women seeking an abortion. 
Moreover, as half of unintended pregnancies are due to contraceptive failure, and half of them end in abortion, abortion clinics may have significant relevance and potential impact when advising post-abortion contraceptive methods.

In this study, the women residing within 30 minutes of walking distance to the government health facility with IUCD services were twice as likely to use IUCD as the ones without the services. In another urban setting study based in Kathmandu Valley, Nepal; the women were more likely to use IUCD if IUCD services were available in their nearest family planning centers. ${ }^{21}$ The availability of the service and commodities required for IUCD insertion is important in many forms. The potential user might not visit another facility for IUCD due to personal reasons of time or travel (money), and thus could end up using least effective methods. Further, the health professional might not want to provide counseling of methods, which are unavailable at their facilities. In a study based in New York City, a physician quoted that unavailability of IUCD was the main barrier to provide IUCD services. ${ }^{27}$

Prior use of modern contraceptive methods did not appear to influence IUCD use in this study. This finding is interesting, as the previous use of FP methods plays an important part in choosing more effective methods for family planning, as shown in studies in Turkey, ${ }^{28}$ Uganda, $^{29}$ and Ethiopia. ${ }^{30}$

In our study, the women who had been counseled about IUCD by health workers were 2.83-times as likely to use IUCD than those who were advised by non-professionals, such as peers, colleagues, or relatives, or who had never heard of it, similar to the study in Ethiopia. ${ }^{22}$ This supports the vital importance of knowledgeable counseling in family planning, as it can increase reproductive health literacy that will ultimately empower them to choose the best contraceptive method available.

This study showed that the women who had a good knowledge level about IUCD as a method of modern contraceptive were 2.85-times more likely to use IUCD than those who had a poor level or no knowledge about it, which was very much similar to a study in Ethiopia. ${ }^{22}$ The good knowledge level means increased awareness about the method's safety, effectiveness, and its advantage over other methods, inferring the likeliness of its uptake. A study in rural India ${ }^{31}$ showed that lack of knowledge regarding mechanisms and side-effects of temporary methods limits the demand of the contraception.

\section{Conclusion}

The study shows that the awareness about IUCD as a contraceptive method is not merely sufficient for its utilization. The educational status of women and their husband, supportive husband, as well as knowledge on its safety and efficacy is critical in increasing the likelihood of utilization of IUCD. The use of IUCD among women with a history of abortion needs further exploration. However, competent counseling and universal access are also instrumental in increasing the utilization of IUCD.

\section{Acknowledgments}

The authors would like to acknowledge the Central Department of Public Health, Maharajgunj Medical Campus, Institute of Medicine, Tribhuvan University, all staff of the institutional clinic and the participants of this study. Special mention goes to Ms Upasana Ghimire and Ms Namuna Shrestha for their precious time during the data collection. The authors would also like to wholeheartedly thank Professor Dr Barbara J Engebretsen for proofreading the manuscript.

\section{Disclosure}

The authors report no conflicts of interest in this work.

\section{References}

1. World Health Organization. Family planning/Contraception. Fact Sheets; 2018. Available from: https://www.who.int/news-room/fact-sheets/detail/ family-planning-contraception. Accessed November 22, 2018.

2. Starbird E, Norton M, Marcus R. Investing in family planning: key to achieving the sustainable development goals. Global Health. 2016;4 (2):191-210.

3. Sedgh G, Singh S, Hussain R. Intended and unintended pregnancies worldwide in 2012 and recent trends. Stud Fam Plann. 2014;45 (3):301-314. doi:10.1111/j.1728-4465.2014.00393.x

4. Gipson JD, Koenig MA, Hindin MJ. The effects of unintended pregnancy on infant, child, and parental health: a review of the literature. Stud Fam Plann. 2008;39(1):18-38.

5. Finer LB, Henshaw SK. Disparities in rates of unintended pregnancy in the United States, 1994 and 2001. Perspect Sex Reprod Health. 2006;38(2):90-96. doi:10.1363/psrh.38.090.06

6. Puri M, Singh S, Sundaram A, Hussain R, Tamang A, Crowell M. Abortion incidence and unintended pregnancy in Nepal. Int Perspect Sex Reprod Health. 2016;42(4):197. doi:10.1363/42e2116

7. United Nations Department of Economics and Social Affairs. Trends in Contraceptive Use Worldwide: 2015. Population Division; 2015.

8. Ministry of Health, Nepal, New ERA, ICF. Nepal Demographic and Health Survey 2016. Kathmandu, Nepal: Ministry of Health, Nepal; 2017.

9. Stoddard A, McNicholas C, Peipert JF. Efficacy and safety of longacting reversible contraception. Drugs. 2011;71(8):969-980. doi:10.2165/11591290-000000000-00000

10. American College of Obstetricians and Gynecologists Committee Opinion No. 735. Adolescents and long-acting reversible contraception: implants and intrauterine devices. Obstet Gynecol. 2018;131(5): e130-e139. 
11. World Health Organization. Medical Eligibility Criteria for Contraceptive Use. 5th ed. World Health Organization; 2015.

12. Taye A, Woldie M, Sinaga M. Predictors of long acting reversible contraceptive use among married women visiting health facilities in Jimma Town. J Women's Health Care. 2014;4:1.

13. World Health Organization. Emergency contraception. Fact Sheets; 2018. Available from: https://www.who.int/news-room/fact-sheets/ detail/emergency-contraception. Accessed September 13, 2018.

14. Espey E, Ogburn T. Long-acting reversible contraceptives: intrauterine devices and the contraceptive implant. Obstet Gynecol. 2011;117 (3):705-719. doi:10.1097/AOG.0b013e31820ce2f0

15. Department of Health Services (DoHS). Annual Report 2014/15. Kathmandu, Nepal: Ministry of Health, Government of Nepal; 2016.

16. Sharma M, Joshi S, Nagar O, Sharma A. Determinants of intrauterine contraceptive device discontinuation among Indian women. $J$ Obstetr Gynecol India. 2014;64(3):208-211. doi:10.1007/s13224-014-0516-5

17. Azmat SK, Shaikh BT, Hameed W, et al. Rates of IUCD discontinuation and its associated factors among the clients of a social franchising network in Pakistan. BMC Women's Health. 2012;12(1):8. doi:10.1186/1472-6874-12-8

18. Thapa S, Paudel IS, Bhattarai S, Joshi R, Thapa K. Factors affecting IUCD discontinuation in Nepal: a nested case-control study. Asia Pac J Publ Health. 2015;27(2):NP1280-NP1287. doi:10.1177/1010539 512458522

19. Thapa S. Early discontinuation of intrauterine device in Nepal-a retrospective study. WHO Chron. 2012;1(3):309-319.

20. Chakraborty NM, Murphy C, Paudel M, Sharma S. Knowledge and perceptions of the intrauterine device among family planning providers in Nepal: a cross-sectional analysis by cadre and sector. $B M C$ Health Serv Res. 2015;15(1):39. doi:10.1186/s12913-015-0718-2

21. Joshi R, Bhattarai S, Simkhada K, Thapa S. Determinants of intrauterine contraceptive device use among the women of urban areas of Nepal. Nepal J Obstetr Gynaecol. 2013;8(2):16-20. doi:10.3126/ njog.v8i2.9760
22. Animen S, Lake S, Mekuriaw E. Utilization of intra uterine contraceptive device and associated factors among reproductive age group of family planning users in Han Health Center, Bahir Dar, North West Amhara, Ethiopia, 2018. BMC Res Notes. 2018;11(1):922. doi:10.1186/s13104-018-4032-z

23. Central Bureau of Statistics (CBS). Nepal multiple indicator cluster survey 2014. Final Report. Nepal: Central Bureau of Statistics and UNICEF Nepal Kathmandu; 2015.

24. Rose SB, Cooper AJ, Baker NK, Lawton B. Attitudes toward longacting reversible contraception among young women seeking abortion. $J$ Women's Health. 2011;20(11):1729-1735. doi:10.1089/jwh.2010.2658

25. Luo Z, Gao L, Anguzu R, Zhao J. Long-acting reversible contraceptive use in the post-abortion period among women seeking abortion in mainland China: intentions and barriers. Reprod Health. 2018;15(1):85. doi:10.1186/s12978-018-0543-2

26. Okusanya BO, Oduwole O, Effa EE. Immediate postabortal insertion of intrauterine devices. Cochrane Lib. 2014.

27. Rubin SE, Davis K, McKee MD. New york city physicians' views of providing long-acting reversible contraception to adolescents. Ann Fam Med. 2013;11(2):130-136. doi:10.1370/afm.1450

28. Ozalp S, Yalcin OT, Hassa H, Erbay B, Dalan N. Factors affecting the contraceptive choice in a developing country. Int J Gynaecol Obstet. 1999;65(1):53-57. doi:10.1016/s0020-7292(99)00010-7

29. Sileo KM, Wanyenze RK, Lule H, Kiene SM. Determinants of family planning service uptake and use of contraceptives among postpartum women in rural Uganda. Int J Public Health. 2015;60(8):987-997. doi:10.1007/s00038-015-0683-x

30. Gebremedhin AY, Kebede Y, Gelagay AA, Habitu YA. Family planning use and its associated factors among women in the extended postpartum period in Addis Ababa, Ethiopia. Contraception Reprod Med. 2018;3:1. doi:10.1186/s40834-017-0054-5

31. Hall MAK, Stephenson RB, Juvekar S. Social and logistical barriers to the use of reversible contraception among women in a rural Indian village. J Health Popul Nutr. 2008;26(2):241.

\section{Publish your work in this journal}

Open Access Journal of Contraception is an international, peerreviewed, open access, online journal, publishing original research, reports, reviews and commentaries on all areas of contraception. In addition to clinical research, demographics and health-related aspects, the journal welcomes new findings in animal and preclinical studies relating to understanding the biological mechanisms and practical development of new contraceptive agents. The manuscript management system is completely online and includes a very quick and fair peer-review system. Visit http://www.dovepress.com/testimonials. php to read real quotes from published authors. 